\title{
Analysis of Heat Pump Condenser's Performance using the Mathematical Model and a Numerical Method
}

\section{Jozsef Nyers}

Óbuda University, Budapest, Bécsi út 96, 1034 Budapest, Hungary

Subotica Tech, Marko Oreskovic 16, 24000 Subotica, Serbia

e-mail: jnyers@vts.su.ac.rs

\section{Laszlo Garbai}

Budapest University of Technology and Economics, 1111 Budapest, Müegyetem rkp. 3-9, Hungary; e-mail: garbai@epgep.bme.hu

\section{Arpad Nyers}

Subotica Tech, Marko Oreskovic 16, 24000 Subotica, Serbia

Tera Term co., Vig Istvan 1, 24000 Subotica, Serbia

e-mail: nyarp@vts.su.ac.rs

\begin{abstract}
: this article aims to investigate the performance of the heat pump's condenser and functionality, suitability of the steady-state mode mathematical model and the used numerical method. The heat transferred through the condenser is the performance of the condenser. The condenser is plate exchanger. The refrigerant is $R 134 a$ and the heated medium is water. This wide-range study investigates the condenser's performance depending on four independent external variables. The independent external variables are: inlet temperature of the refrigerant, refrigerant mass flow rate, the water inlet temperature and the water mass flow rate.The investigation is carried out by using a steady state mode mathematical model with lumped parameter. The model consists of two parts. Part one describes mathematically the cooling of the superheated vapor, while the second part describes the condensation itself. The physical model is simple, only the plate condenser and the input, output parameters are included. This article does not take into consideration the compressor and circulating pump model. That remains the subject of future investigation. The results can be represented in three-dimensional graphics. For example, it shows the changes of heat transfer in the condenser depending on the refrigerant mass flow rate and the water mass flow rate.
\end{abstract}


Keywords: condenser; heat pump; circulator pump; performance; mathematical model; mass flow rate; efficiency

\section{Nomenclature}

$\dot{m} \quad$ mass flow rate $[\mathrm{kg} / \mathrm{s}]$

$\alpha \quad$ convective heat transfer coefficient $\left[\mathrm{W} / \mathrm{m}^{2} /{ }^{\circ} \mathrm{C}\right]$

$\lambda \quad$ conductive heat transfer coefficient $\left[\mathrm{W} / \mathrm{m} /{ }^{\circ} \mathrm{C}\right]$

$k \quad$ overall heat transfer coefficient $\left[\mathrm{W} / \mathrm{m}^{2} /{ }^{\circ} \mathrm{C}\right]$

$C_{p} \quad$ specific heat, $\mathrm{p}=$ const $\left[\mathrm{J} / \mathrm{kg} /{ }^{\circ} \mathrm{C}\right]$

$t \quad$ temperature $\left[{ }^{\circ} \mathrm{C}\right]$

$\Delta t \quad$ temperature difference $\left[{ }^{\circ} \mathrm{C}\right]$

$F \quad$ surface $\left[\mathrm{m}^{2}\right]$

$A \quad$ cross section area of flow $\left[\mathrm{m}^{2}\right]$

di latent heat $[\mathrm{J} / \mathrm{kg}]$

$q \quad$ heat flux, performance $[W]$

Re Reynolds number [-]

Pr Prandtl number [-]

$C \quad$ coefficient $\left[\mathrm{s} / \mathrm{kg}^{2} / \mathrm{m}\right]$

$\rho \quad$ density $\left[\mathrm{kg} / \mathrm{m}^{3}\right]$

$\delta \quad$ thickness $[\mathrm{m}]$

$d$ diameter $[m]$

$\xi \quad$ coefficient of flow resistent [-]

Subscripts and superscripts

$\begin{array}{ll}\mathrm{v} & \text { water } \\ \mathrm{f} & \text { refigerant (freon) } \\ \mathrm{i} & \text { input } \\ \mathrm{o} & \text { output } \\ \mathrm{m} & \text { middle } \\ 1 & \text { vapor cooling section } \\ 2 & \text { condensation section } \\ \mathrm{p} & \text { pressure }\end{array}$

\section{Introduction}

The condenser plays a decisive role to the efficiency of the heat pump. The heat transfer between the refrigerant and the heated water is formed in the condenser. The efficiency of the heat transfer process is very important. On the efficiency of the heat transfer process have strong effects the construction of the condenser, the refrigerant and the heated water mass flow rate.

The answer to the extensive investigation of the interactions among the operating condenser's parameters can be obtained by measurements or by the solution of the mathematical model. The mathematical model have been developed to correspond 
to the above-defined tasks. In the center of the mathematical model is the condenser as well as the refrigerant and water to transport the heat.This study does not take into consideration the compressor's and circulating pump's physical and mathematical model. It is the topics of the future investigation.

The investigated condenser is plate exchanger. Within the condenser during the processing are formed two parts. The first part is the superheated vapor cooling section, the second is the condensation section itself. The aim of research is to investigate the interaction of condenser and its environment in terms of energy efficiency. More precisely, the determination and investigation of condenser's coefficient of performance-COP depending on the compressor and circulating pumps. In this paper the influence of the compressor and circulation pump on the perfomances of the condenser is taken into account through the mass flow rate and inlet temperature of the refrigerant and hot water.The investigation of the COP can only be justified in steady state operation mode. The transitional operation mode occurs only in the case of switching the heat pump on/off and possibly in the case of changing the system parameter in the time.

On the base the above specified aim the mathematical model is steady state, with lumped parameter and coupled algebraic equations. In the mathematical model the equations are divided into the governing and auxiliary equations. The governing are the energy balance equations for the heated water and the refrigerant. The auxiliary equation are the equations of the convective heat transfer coefficients and the latent heat of the refrigerant. In the studied system four independent variables are present, the refrigerant mass flow rate, the refrigerant inlet temperature, the water mass flow rate and the water inlet temperature. Changing the independent variables the condenser's performance and the coefficient of performance-COP or rather energy efficiency can be changed, as well.

In principle, each of the four independent variables can be changed simultaneously but in this case separatly the effect of the variables to the condenser performance will not be possible to detect. It is preferred to change two independent variables at the same time during the investigation of the condenser performance. Four possible combinations exist when two system parameters is changing. But the most physically relevant investigation is the change of the heat transfer in condenser depending on the refrigerant mass flow rate and the heated water mass flow rate.

Furthermore, the simulation of the remaining three possible combinations is also carried out. This was the change of heat transfer in condeser depending on the refrigerant mass flow rate and inlet temperature, the water mass flow rate and inlet temperature as well as the refrigerant and water inlet temperature.

To solve the system of equations in the created mathematical model in algebraic form is almost not possible. Some numerical method is applicable only. The Newton-Taylor numerical method was used to solve the system of equation. The obtained numerical results can be displayed in a very suitable three dimensioned 
form. The great advantage of graphics is that the behavior of the condenser's performance can be seen over a wide range of the parameters.

In the scientific press has many articles researched the heat pump's behavior in stationary operating mode used various mathematical models with lumped parameters. Many of the mathematical models contain all four components including the condenser, however, the goal of research is focused on the behavior of the entire system rather than individual components. A smaller number of articles that dealt with the study of the condenser 's behavior as a component of a heat pump.

Hatef Madani and al. [1]. Have dealt with the investigation of control of the heating system using heat pump. In order to investigate the control of the system are developed a mathematical model with lumped parameters and for stationary regime. As part of the complete mathematical model developed the mathematical model of the condenser, too. The description of the condenser are used well known equations based on conservation energy. As a system parameter used enthalpy. Elias Kinab and al. [2]. Their aim was investigating the optimal seasonal performance of reversible heat pump system. Mathematical model of the condenser is created in analytical form based on the data of the existing physical condenser. Hongtao Qiao and al. [3]. Set a new mathematical model of the convective heat transfer coefficient to the refrigerant and water within the plate condenser. Róbert Santa [4]. Compared the results of condensing heat transfer coefficients of several authors. According to him paper the best characteristics showed Shah model among the investigated models. Yi-Yie Yan and al. [5]. Created a new mathematical model of condensing heat transfer coefficient of the

plate condenser and carried out the model verification at the factory realized condenser.

The above articles mainly investigated the processes within the condenser in terms of the heat exchange and the results are presented in two-dimensional graphics. In the enclosed article, research has focused on investigate the efficiency of heat exchange in the condenser but as a function of external influences.

Results obtained by numerical simulation are presented in the three-dimensional graphics. Three-dimensional graphics are very suitable for the analysis because it provides a wide range of possibilities of displaying heat efficiency of the condenser, depending on the two external influences the same time.

\section{Physical Model}

The physical model includes the condenser, the refrigerant and the water for transport the heat. The created model does not include the compressor and circulating pump. The compressor and circulating pump's effect on the condenser's performance through the refrigerant and the water mass flow rate and 
inlet temperature. The investigated condenser is plate heat exchanger. Inside the condenser the refrigerant and the water may stream in the co-current or countercurrent direction.

The direction of the stream has a negligibly small effect on the condenser's performance because the temperature of the condensation can be considered as constant. The near constant temperature is the result of the low pressure drop across the condensor. In the superheated vapor cooling section the counter flow is more preferable. The four independent variables are the refrigerant and the water mass flow rate and the inlet temperature. These four variables can be changed independently of each other.

Incorporating the compressor and circulation pump in a mathematical model situation something is changing. Independent variable mass flow rate of water will be dependent on the performance of the circulating pump, and refrigerant's mass flow rate, of the compressor's performance.

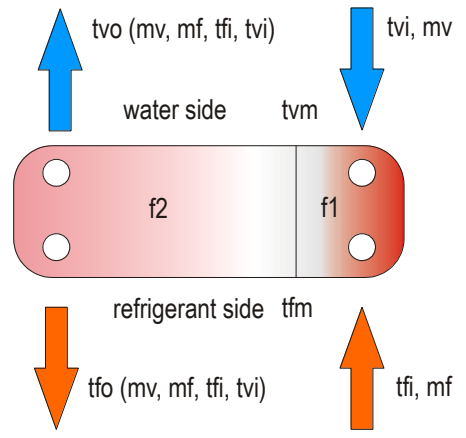

Figure 1

Heat Pump's Condenser with flow of refrigerant and hot water

\section{Mathematical Model}

\subsection{General Description}

The condenser's mathematical model was developed with lumped parameters and on steady-state operation mode. The governing equations are formed based on the energy balance equations separately on the vapor section, and separately on the condensate section.

Within each section three balance equations can be formed. The balance equation of refrigerant, water, and the balance equation of the heat transfer between them. By analyzing the energy efficiency only the steady-state operation mode is interesting. The dynamic-state may take up to $1 \%$ of the operation time. 


\subsection{Approximations}

The next approximations have been applied during the modeling.

- lumped parameters

- steady-state operation mode

- pressure drop in plate exchanger is small therefore are neglected.

- the condenser's wall thermal resistance is too small so it has been neglected.

- specific heat of water is taken as constant because weakly depends on the temperature.

- specific heat of refrigerant vapor is taken as constant because weakly depends on the temperature.

- the condenser's heat loss to the environment is neglected.

\subsection{The Governing Equations}

\subsubsection{Vapor Cooling Section}

Heat delivered by the refrigerant vapor.

$q_{1}=C_{p f} \cdot \dot{m}_{f} \cdot \Delta t_{f 1}$

Heat transferred through the condenser in the vapor cooling section.

$q_{1}=k_{f 1} \cdot F_{1} \cdot \Delta t_{\ln 1}$

Heat received by the water.

$q_{1}=C_{p v} \cdot \dot{m}_{v} \cdot \Delta t_{v 1}$

\subsubsection{Condensing Section}

Heat delivered by the condensation of the refrigerant.

$q_{2}=\dot{m}_{f} \cdot \Delta i_{f}$

Heat transferred through the condenser in the condensation section.

$q_{2}=k_{f 2} \cdot F_{2} \cdot \Delta t_{\ln 2}$

Heat received by the water.

$\mathrm{q}_{2}=\mathrm{C}_{\mathrm{pv}} \cdot \dot{\mathrm{m}}_{\mathrm{v}} \cdot \Delta \mathrm{t}_{\mathrm{v} 2}$

\subsection{Auxiliary Equations}

Logarithmic mean temperature difference

$\Delta t_{\text {ln }}=\frac{\Delta t_{\text {max }}-\Delta t_{\text {min }}}{\ln \frac{\Delta t_{\max }}{\Delta t_{\min }}}$ 
Overall heat transfer coefficient

$k=\frac{1}{\frac{1}{\alpha_{v}}+\sum \frac{\delta}{\lambda}+\frac{1}{\alpha_{f}}}=\frac{\alpha_{v} \cdot \alpha_{f}}{\alpha_{v}+\alpha_{f}}$

The water's convective heat transfer coefficient. [4]

$\alpha_{v}=0.2121 \cdot \frac{\lambda_{v}}{d_{e k v}} \cdot R e_{v}^{0.78}\left(\dot{m}_{v}\right) \cdot P r_{v}^{1 / 3}$

The refrigerant vapor's convective heat transfer coefficient when $x=1$. [4]

$\alpha_{f s}=4.118 \cdot \frac{\lambda_{f l}}{d_{e k v}} \cdot R e_{f}^{0.4}\left(\dot{m}_{f}, x\right) \cdot \operatorname{Pr}_{f l}^{1 / 3}$

The condensing heat transfer coefficient is the arithmetic mean value by increment $\mathrm{dx}=0.1$ for the interval $\mathrm{x}=0-1$. Using equation (10) [4]

$\alpha_{f}=\frac{\sum_{i=0}^{i=n} \alpha_{f s}\left(\dot{m}_{f}, x_{i}\right)}{n+1}$

$x_{i+1}=x_{i}+d x$

$$
x_{0}=0, \quad x_{n}=1, \quad d x=0.1
$$

The latent heat as the function of the condensation temperature.

$\mathrm{di}=\mathrm{a}_{\mathrm{o}}+\mathrm{a}_{1} \cdot \mathrm{t}_{\mathrm{fo}}^{1}+\mathrm{a}_{2} \cdot \mathrm{t}_{\mathrm{fo}}^{2}$

Where the constants of the refrigerant $\mathrm{R} 134 \mathrm{a}$ are:

$\mathrm{a}_{\mathrm{o}}=200.5965715$

$\mathrm{a}_{1}=-0.709168$

$\mathrm{a}_{2}=-0.00596796$

The condenser's total surface.

$F=F_{1}+F_{2}$

The total amount of heat transferred through the surface of the condenser.

$q=q_{1}+q_{2}$

\subsection{The Condition of Linking the Two Parts of Model}

Change of refrigerant phase are the cause of the forming two parts of the model. The condition of linking the two parts of the model is the condensing temperature and the temperature of the cooled refrigerant vapor on the end of first section must to be equal

$t_{f m}=t_{f o}$ 


\section{Mathematical Method}

A mathematical model of the heat pumps condenser based on lumped parameters and in steady-state. The model is stationary so the parameters do not depend on the time or on space because the parameters are lumped. Thanks to these two assumptions, equations in the model are in algebraic format, without exception. Regardless, analytically to solve the mentioned mathematical model due to the complexity is not possible.

The model's complexity and size has almost no restrictions imposed on the numerical method. The mathematical equations in the model can be coupled, nonlinear and implicit. Applied numerical method is iterative therefore it must be assumed the appropriate initial solutions.

The non-linear system of equations has multiple solutions so the initial values have to be determined properly. The solution of the non-linear system of equations converges to the initial value but maybe it is not the right solution. In such a case, the initial values have to be changed.

In this study, a well-known numerical method, such as the Newton linearization and Gauss elimination method has been applied. The governing equations are connected and must be arranged in implicit form. Before the starts of the first iteration each variable should get the initial value. As it was noted earlier, the system of equations is non-linear therefore it is very important to determine the initial value of the solutions.

The simulation is running in a wide range and in three dimensions. Simulations made 900 calculated points. The calculation of the variables in every pont is done iteratively, while the calculation of the next point can be considered a recursive step, since the initial values of solution was equalized with the final results from the previous step. This solution offeres a convergence and that is good if the initial values of solution are close to the values of the solution.

\subsection{Implicit Mathematical Model of the Condenser}

The condition of using the Newton-Taylor's linearisation method the equations must be written in an implicit form.

$$
\begin{aligned}
& f_{1}=-q_{1}+C_{p f} \cdot \dot{m}_{f} \cdot \Delta t_{f 1}=0 \\
& f_{2}=-q_{1}+k_{f 1} \cdot F_{1} \cdot \Delta t_{l n 1}=0 \\
& f_{3}=-q_{1}+C_{p v} \cdot \dot{m}_{v} \cdot \Delta t_{v 1}=0 \\
& f_{4}=-q_{2}+\dot{m}_{f} \cdot \Delta i_{f}=0 \\
& f_{5}=-q_{2}+k_{f 2} \cdot F_{2} \cdot \Delta t_{l n 2}=0 \\
& f_{6}=-q_{2}+C_{p v} \cdot \dot{m}_{v} \cdot \Delta t_{v 2}=0 \\
& f_{7}=-d i+a_{o}+a_{1} \cdot t_{f o}^{1}+a_{2} \cdot t_{f o}^{2}=0
\end{aligned}
$$




\subsection{Newton-Taylor's Linearisation Method of Implicit Non- Linear Equations}

The (16) - (22) implicit equations have to develope in the Taylor series. Implicit discretized equation after developed in the Taylor series in $1+\mathrm{i}$ iteration.

$f_{i+1}=f_{i}+\frac{\partial f_{i}}{\partial x} \cdot d x+\cdots$

From the above relation the increment of variable between $i$ and $i+1$ iterations can be expressed.

$d x=\frac{f_{i+1}-f_{i}}{\frac{\partial f_{i}}{\partial x}}$

In the $\mathrm{i}+1$ iteration, the new initial values of the variables

$x_{i+1}=\mathrm{dx}+x_{i}$

\section{Simulations}

Several independent variables were investigated to explain the behaviour of the heat pump's condenser. The investigations carried out by the mathematical model and the numerical method.

The independent variables are:

- the compressor output parameters, the refrigerant mass flow and the superheated vapor temperature.

- the hot water flow rate circulated circulation pump and inlet temperature.

The condensator performance was simulated in three dimensions.

The simulation includes the following investigations:

a. The condenser performance as a function of the heated water mass flow rate and refrigerant mass flow rate.

$q=f\left(\dot{m}_{f}, \dot{m}_{v}\right)$

b. The condenser performance as a function of the heated water and the refrigerant inlet temperature.

$q=f\left(t_{f i}, t_{v i}\right)$

c. The condenser performance as a function of the refrigerant mass flow of superheated vapour temperature.

$q=f\left(\dot{m}_{f}, t_{f i}\right)$ 
d. The condenser performance as a function of the heated water mass flow rate, the inlet temperature

$q=f\left(\dot{m}_{v}, t_{v i}\right)$

\section{Simulation Results}

On the basis of the created mathematical model, the Newton-Taylor linearisation and Gauss iteration the obtained results are presented in the Figures 2, 3, 4.

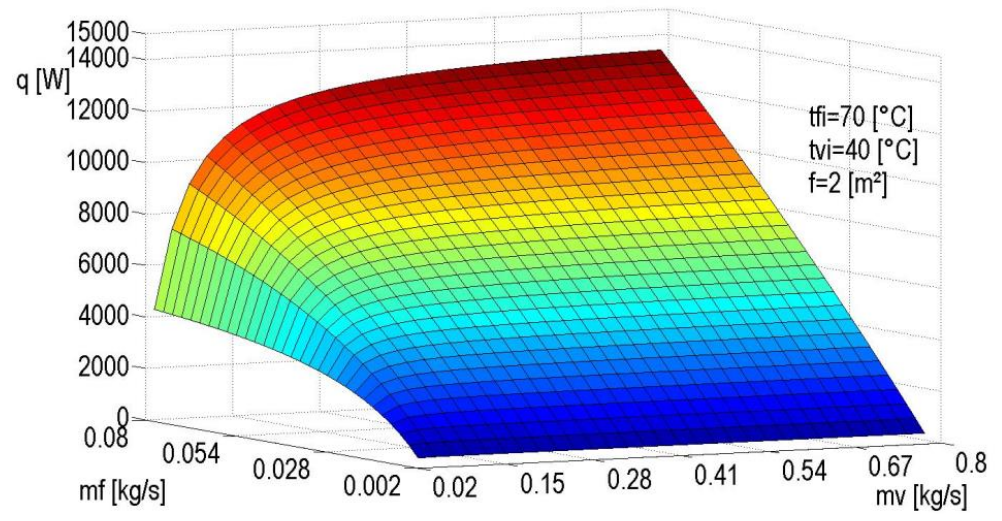

Figure 2

Condenser's performance as a function of the hot water and the refrigerant mass flow rate

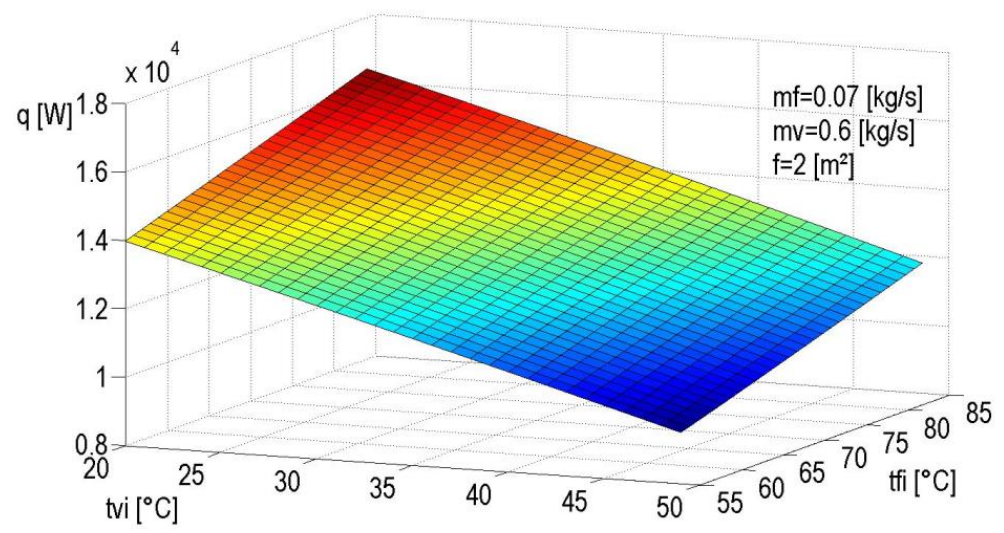

Figure 3

Condenser's performance as a function of the hot water and the refrigerant mass flow rate 




Figure 4

Condenser's performance as a function of the hot water mass flow rate and the inlet temperature

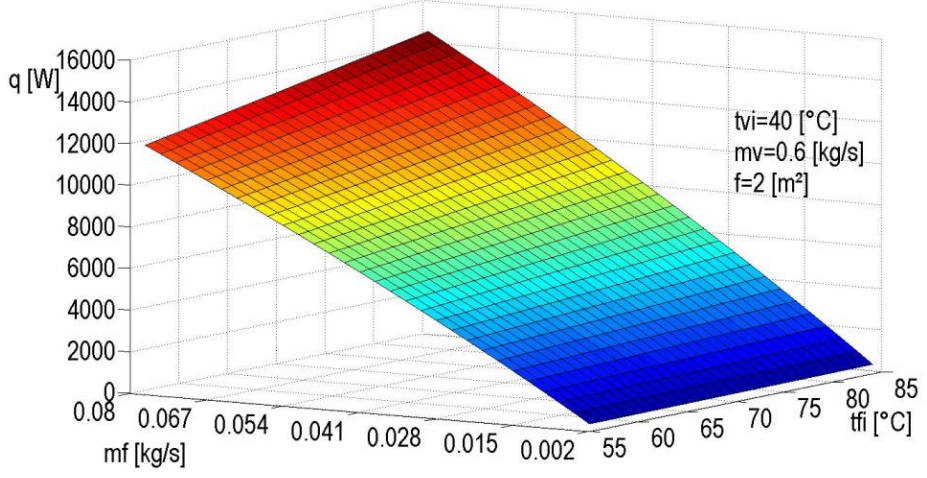

Figure 5

Condenser's performance as a function of the refrigerant mass flow rate and the inlet temperature

\section{Conclusions}

\section{a. Comments on the mathematical model}

- the mathematical model is stationary with lumped parameters

- difference of temperatures is logarithmic

- the convective heat transfer coefficients depends on the mass flow rate

- latent heat depends on the condensation temperature

- the thermal resistance of the thin wall of condenser is very small, therefore it has been neglected.

\section{b. Comments on the numerical methods}

- the numerical method is iterative with Newton-Taylor linearization and Gaussian elimination method. 
- the values of the finally numerical solutions largely depend on the initial solutions.

- in the case of improper initial solutions, the obtained solutions are not physically appropriate.

- the investigation of the obtained numerical results is possible in graphical form

- the applied graphics are three-dimensional

\section{c. Simulation results}

- the created mathematical model and the applied numerical method provide a wide range of opportunities to investigate the heat pump's plate condenser in the steady-state operating mode

- the research extended to investigate the plate condenser performance as a function of independent input variables.

- the independent input variables are the refrigerant and water mass flow rates and temperatures.

\section{Based on the simulation results, the conclusions are as follows:}

a. The condenser's performance increases nonlinearly as a function of hot water and refrigerant mass flow rate.

b. In the case of zero mass flow rates the condenser performance is zero. For the range of low quantity of the mass flow rates, the performance improvement is extremely intense.

c. The further linear increase in the mass flow rates resulted an asymptotic increasing of performance. It is not worth increasing the mass flow rates after certain quantity because the increase of performance is negligibly little. The investment in flow energy may not be recoverable.

d. The condenser's performance mildly linearly increases as a function of the hot water and the refrigerant temperature difference.

e. The condenser's performance nonlinearly increases depending on the increases of the hot water mass flow rate.

f. If the water inlet temperature increases, the performance decreases proportionally.

g. The condenser's performance weakly non-linear increases if the refrigerant mass flow rate in growth. The increases of the refrigerant's inlet temperature resulted in a clear linear increasing of performance.

\section{New scientific results}

- The new formulation of the investigation of heat pump condenser's performance.

- The condenser is divided into cooling and condensation sections.

- The superheated vapor cooling in the condenser, was taken into account 
- The convective heat transfer coefficients depend on the mass flow rates and temperatures.

- The latent heat depends on the condensing temperature

- For the purpose a suitable complexity mathematical model created

- The model consists of two coupled parts, cooling and condensing section

- The two models are coupled with an internal moving boundary

- Determined the cooling and condensing surface area

- The presentation of the obtained numerical results by three-dimensional graphics

- The new numerical package enables the 3D graphical presentation of results therefore thus provides the comprehensive investigation of condenser's performance and evaluation of new results.

\section{References}

[1] Hatef Madani, Joachim Claesson, Per Lundqvist: „Capacity Control in Ground Source Heat Pump Systems Part I: Modeling and Simulation" I J Refrigeration, Vol 34 (2011), pp 1338-1347

[2] Elias Kinab, Dominique Marchio, Philippe Riviere, Assaad Zoughaib: „Reversible Heat Pump Model for Seasonal Performance Optimization” I J Energy and Buildings, Vol 42 (2010), pp 2269-2280

[3] Hongtao Qiao, Vikrant Aute, Hoseong Lee, Khaled Saleh, Reinhard Radermacher: "A New Model for Plate Heat Exchangers with Generalized Flow Configurations and Phase Change" I J Refrigeration Vol. 36 (2013) pp. 622-632

[4] Róbert Sánta: „The Analysis of Two-Phase Condensation Heat Transfer Models Based on the Comparison of the Boundary Condition" Acta Polytechnica Hungarica Vol. 9, No. 6, 2012, pp 167-180

[5] Yi-Yie Yan, Hsiang-Chao Lio, Tsing-Fa Lin: "Condensation Heat transfer and Pressure Drop of Refrigerant R-134a in a Plate Heat Exchanger" International Journal of Heat and Mass Transfer Vol. 42 (1999) pp 9931006

[6] Imrich Bartal, Hc László Bánhidi, László Garbai: ”Analysis of the Static Thermal Comfort Equation" Energy and Buildings Vol. 49 (2012) pp 188191

[7] Garbai L., Jasper A.: A matematikai rendszerelmélet feldolgozása és alkalmazása épületgépészeti optimalizációs feladatok megoldására; Magyar Épületgépészet LX. évfolyam, 2011/3. szám, pp. 3-6 
[8] Garbai L., Méhes Sz.: Energy Analysis of Geothermal Heat Pump with Utube Installations. IEEE International Symposium CFP 1188N-PRT “EXPRES 2011." Proceedings, pp. 107-112. Subotica, Serbia. 11-12 03. 2011

[9] M. M. Awad, H. M. Mostafa, G. I. Sultan, A. Elbooz, A. M. K. Elghonemy: Performance Enhancement of Air-cooled Condensers, Acta Polytechnica Hungarica, Volume 4, No. 2, pp. 125-142, 2007

[10] Nyers J. Stoyan G.:" A Dynamical Model Adequate for Controlling the Evaporator of Heat Pump", Internationale Journal of Refrigeration, Vol. 17, Issue 2, pp. 101-108, 1994

[11] Nyers J., Nyers A.: "COP of Heating-Cooling System with Heat Pump "IEEE International Symposium CFP 1188N-PRT "EXPRES 2011" Proceedings, pp. 17-21, Subotica, Serbia, 11-12 032011 